\title{
Three-Dimensional Monolithic Organic Battery
}

\section{Electrodes}

Jaegeon Ryu, ${ }^{\dagger}, "$ Byeongho Park,,$"$ " Jieun Kang, ${ }^{,}$Dongki Hong, ${ }^{\S}$ Sung-Dae Kim,${ }^{\perp}$ Jung-Keun Yoo, ${ }^{\star}$ Jin Woo Yi, ${ }^{\star}$ Soojin Park ${ }^{t, *}$ and Youngseok $\mathrm{Oh}^{t, *}$

'Department of Chemistry, Division of Advanced Materials Science, Pohang University of Science and Technology (POSTECH), Pohang 37673, Republic of Korea

Carbon Composites Department, Korea Institute of Materials Science (KIMS), Changwon 51508, Republic of Korea

${ }^{\S}$ Department Energy Engineering, Ulsan National Institute of Science and Technology (UNIST), Ulsan 44919, Republic of Korea

${ }^{\perp}$ Advanced Metals Division, Korea Institute of Materials Science (KIMS), Changwon 51508, Republic of Korea 


\section{Discussion}

\section{Calculation of volumetric capacities regarding Figure $5 \mathrm{~b}$}

There are three different cases in the calculation of volumetric capacities of IBN electrodes and other electrodes listed in Figure 5b; standard electrodes with and without carbon additives, and freestanding electrodes. For the standard electrodes with carbon additives (composite slurry cast on the current collectors, e.g. MGS, GB, and $\mathrm{SnO}_{2} / \mathrm{Si}$ ), the mass of carbon additives (Super P) was excluded when calculating the volumetric (or specific) capacities as the most papers did. However, as the contribution from Super P can be negligible in most articles (less than $200 \mathrm{mAh} / \mathrm{g}$ ), it will not significantly affect the volumetric capacity of entire electrodes (It will rather lower the volumetric capacity). The standard electrode without carbon additives (Si/CNT) showed volumetric and specific capacities including the CNT pillars as a secondary current collector with a primary SS current collector. Although the CNT pillars are excluded from the CNT-Si film after which decreases the thickness of CNT-Si film, it will show totally different electrochemical behaviors and probably severe degradation is expected in such structure to give much lower volumetric capacities. In case of NPSi@C electrode, the mass of carbon coating layers (10-12 wt $\%)$ was excluded. Including the mass of carbon coating layers did not change the volumetric energy densities of above electrodes.

For the freestanding electrodes $\left(\mathrm{Si} / \mathrm{Grn}, \mathrm{TiO}_{2} / \mathrm{Grn}, \mathrm{Fe}_{2} \mathrm{O}_{3} / \mathrm{MWCNT}, \mathrm{Fe}_{3} \mathrm{O}_{4} / \mathrm{Grn}\right.$, and $\mathrm{MnO}_{2} / \mathrm{CNT} / \mathrm{Grn}$ ), they all excluded the mass of carbon materials (Grn or MWCNT). But, again including the mass of carbon coating layers did not change the volumetric energy densities of the above electrodes because it will obey the following equation.

$$
\begin{gathered}
C_{\text {volumetric }}\left(\mathrm{mA} \mathrm{h} \mathrm{cm}^{-3}\right) \\
=C_{\text {specific }}\left(\frac{\mathrm{mA} \mathrm{h}}{g_{\text {active or active }+ \text { carbon }}}\right) \times \text { Areal mass loading }\left(\frac{g_{\text {active or active }+ \text { carbon }}}{\text { Volume }_{\text {constant }}\left(\mathrm{cm}^{3}\right)}\right)
\end{gathered}
$$


In summary, in the constructed electrodes, if calculating the specific capacities and areal mass loading either based on the active materials or active materials with carbon, it does not affect the volumetric capacities as long as the thickness of electrodes remains same. 
Table S1. Summary of porosity analysis on the SWCNT and CIN electrode before and after compression

\begin{tabular}{lcccccc}
\hline Sample & \multicolumn{2}{c}{ SWCNT } & \multicolumn{2}{c}{ CIN10 } & \multicolumn{2}{c}{ CIN20 } \\
& Before & After & Before & After & Before & After \\
\hline SSA $\left(\mathrm{m}^{2} \mathrm{~g}^{-1}\right)$ & 890 & 619 & 755 & 447 & 598 & 209 \\
Pore volume $\left(\mathrm{g} \mathrm{ml}^{-1}\right)^{\mathrm{a}}$ & 1.14 & 0.80 & 1.06 & 0.64 & 0.83 & 0.43 \\
\hline
\end{tabular}

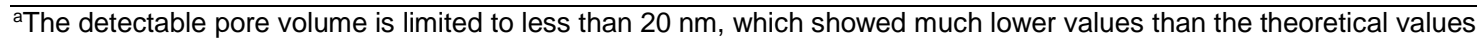

Table S2. Summary of geometric parameters of the SWCNT and CIN electrode before and after compression

\begin{tabular}{lcccccc}
\hline Sample & \multicolumn{2}{c}{ SWCNT } & \multicolumn{2}{c}{ CIN10 } & \multicolumn{2}{c}{ CIN20 } \\
& Before & After & Before & After & Before & After \\
\hline Volume density $\left(\mathrm{mg} \mathrm{ml}^{-1}\right)$ & 7.2 & 1449 & 14.1 & 1250 & 28.4 & 1096 \\
IBN loading density $\left(\mathrm{mg} \mathrm{ml}^{-1}\right)$ & $\mathrm{n} / \mathrm{a}$ & $\mathrm{n} / \mathrm{a}$ & 8.1 & 713 & 22.4 & 866 \\
Average thickness of film $(\mu \mathrm{m})$ & 1,130 & 7 & 1,190 & 14 & 1,200 & 21 \\
IBN areal loading density $\left(\mathrm{mg} \mathrm{cm}^{-2}\right)$ & $\mathrm{n} / \mathrm{a}$ & $\mathrm{n} / \mathrm{a}$ & 0.96 & 1.00 & 2.69 & 1.82 \\
\hline
\end{tabular}




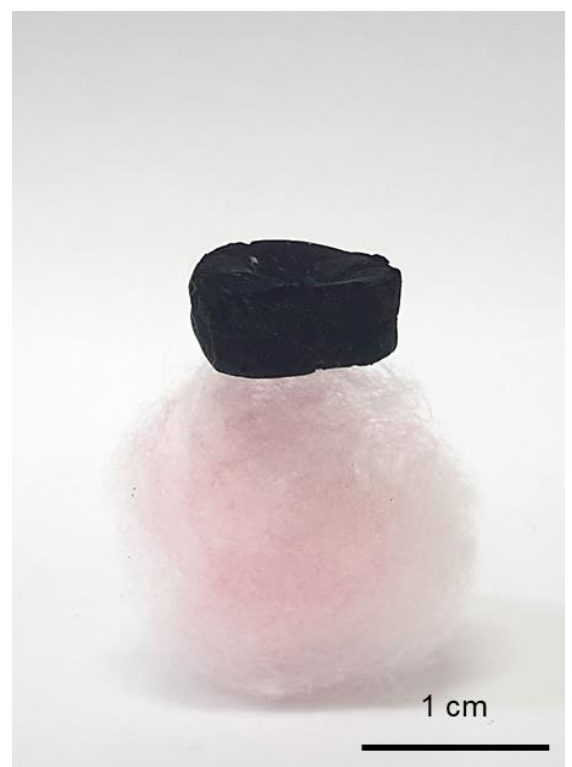

Figure S1. Photograph of the ultralight and conductive large-size CIN electrodes suspended on the cotton wool. 


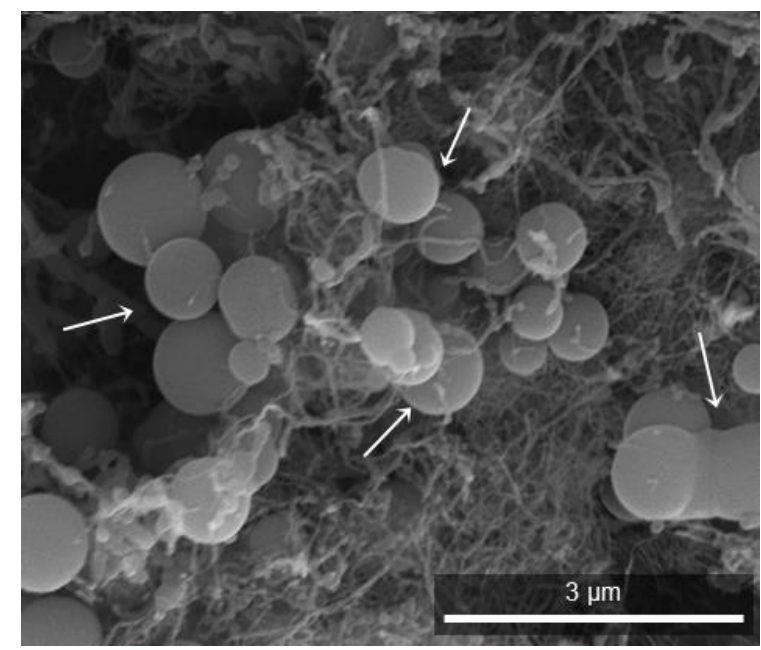

Figure S2. SEM image of the CIN30 sample, showing the formation of polyimide microspheres as an impurity. 
a

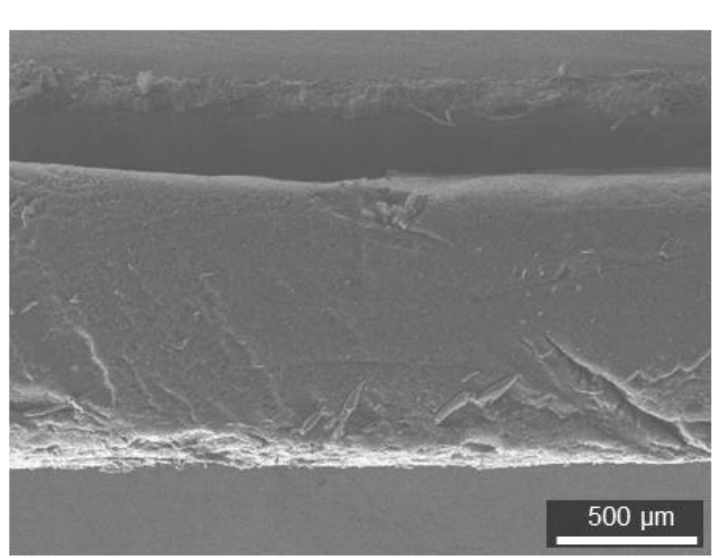

C

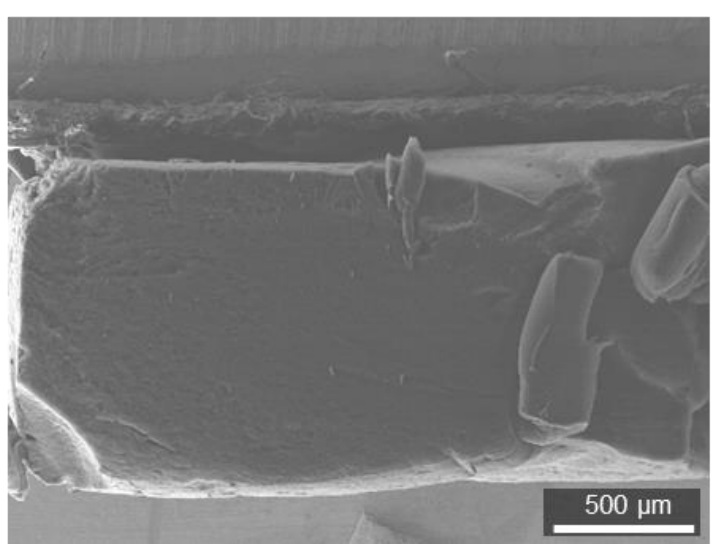

b

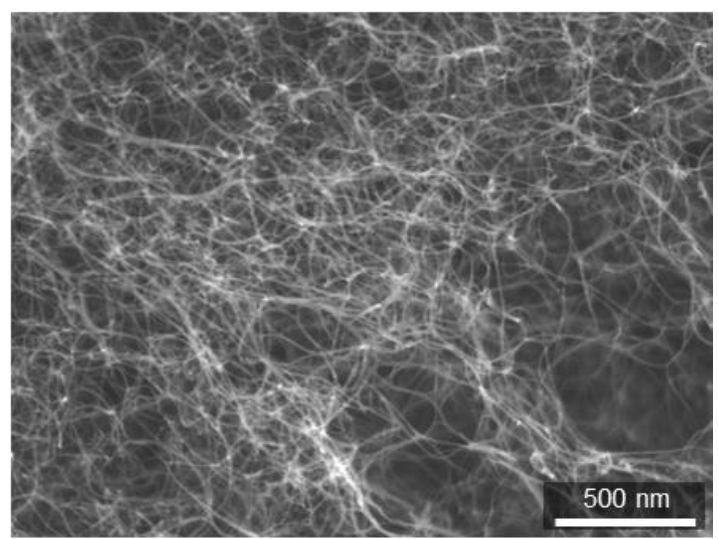

d

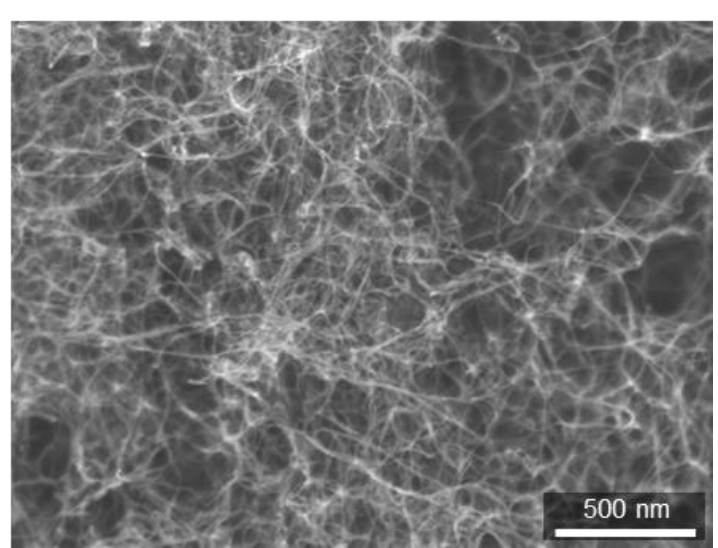

Figure S3. Cross-sectional SEM images of ( $a, b)$ SWCNT aerogel and (c, d) CIN10 aerogel. 
a

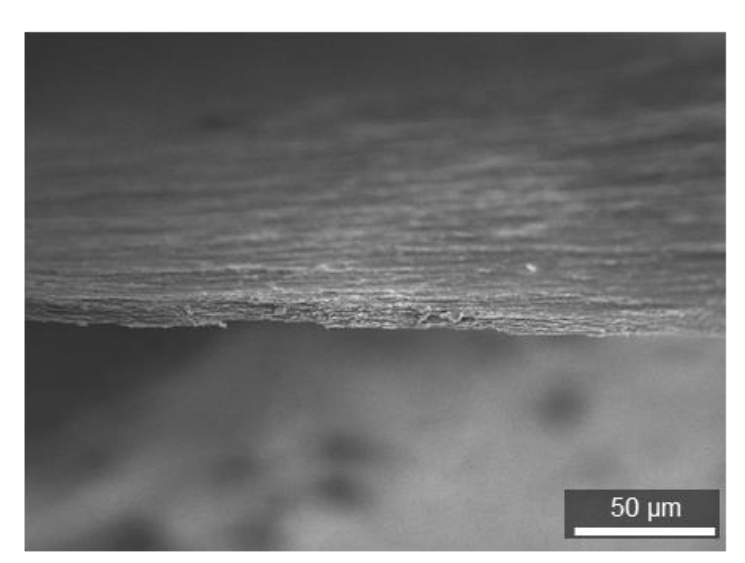

C

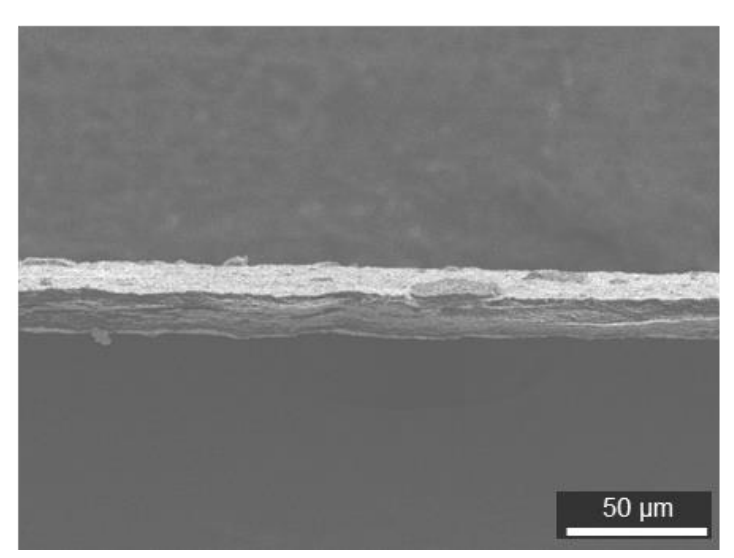

b

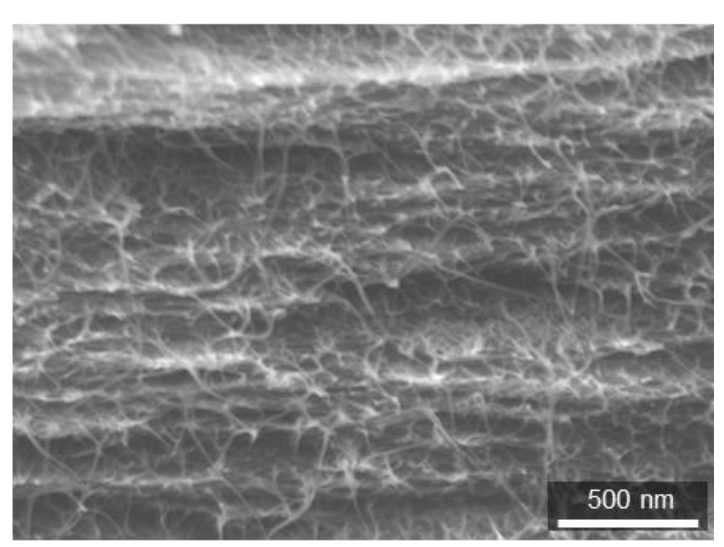

d

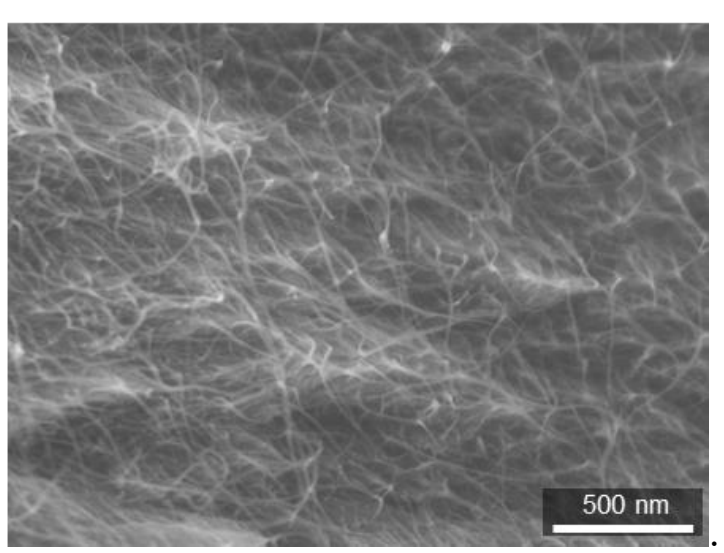

Figure S4. Cross-sectional SEM images of (a, b) SWCNT aerogel and (c, d) CIN10 electrode after the compression. 

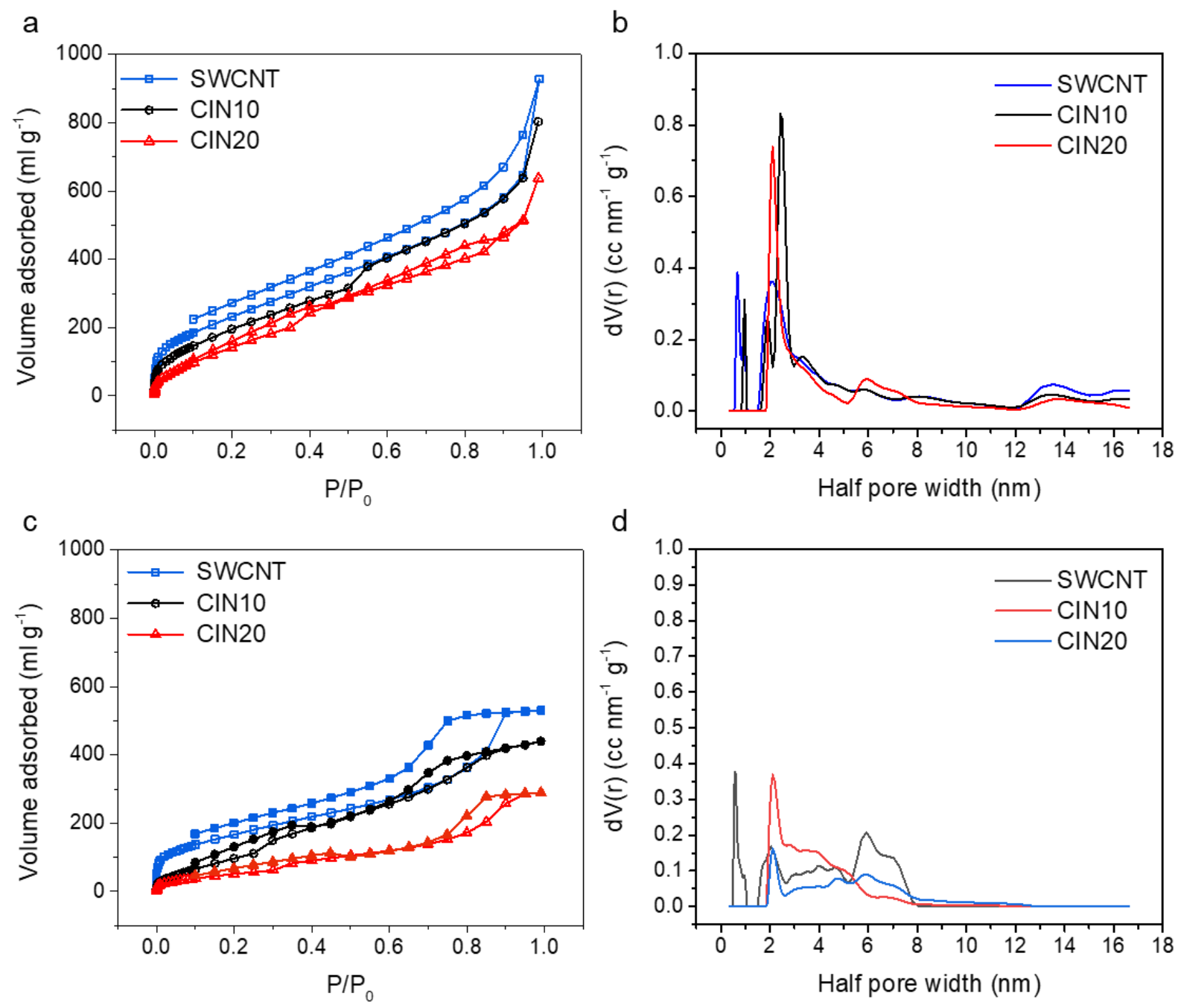

Figure S5. (a, c) Nitrogen adsorption-desorption isotherms and (b, d) DFT pore size distribution curves of pristine SWCNT aerogel, CIN10, and CIN20 electrodes before and after the compression. 

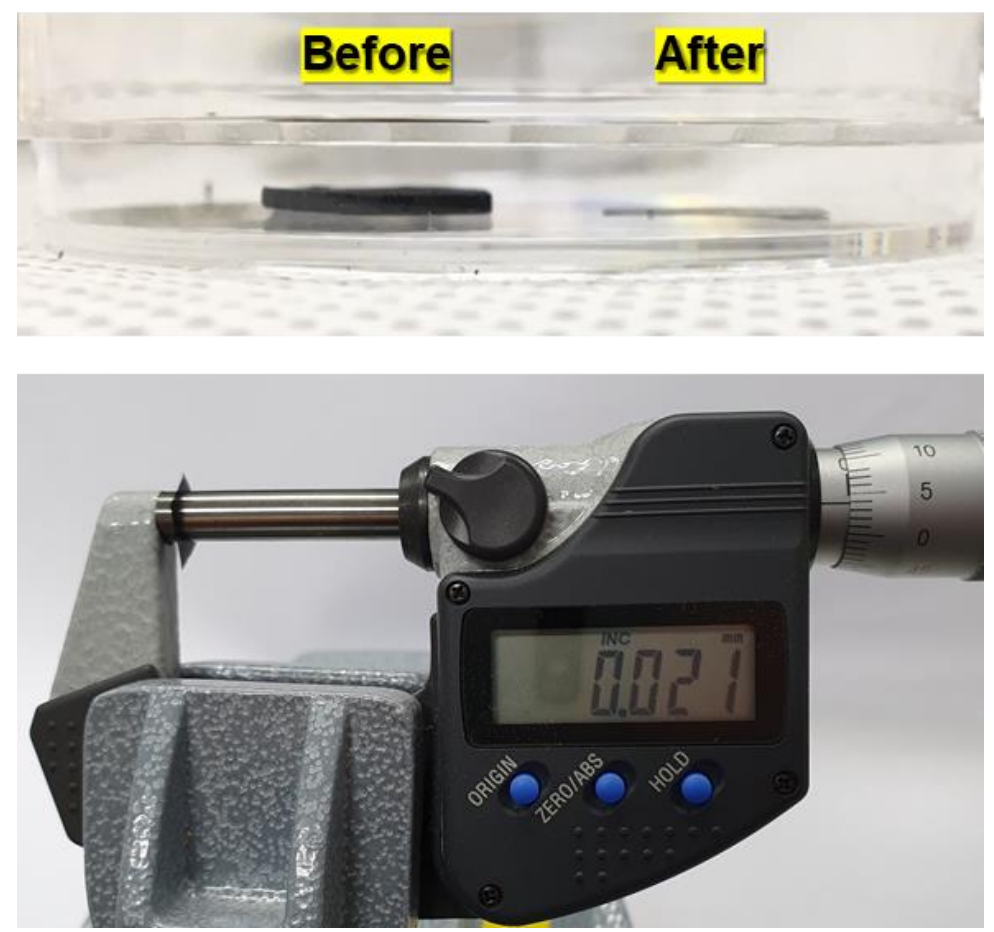

Figure S6. Photographs of cross-view of CIN20 electrode before and after compression and thickness gauge displaying $21 \mu \mathrm{m}$. 

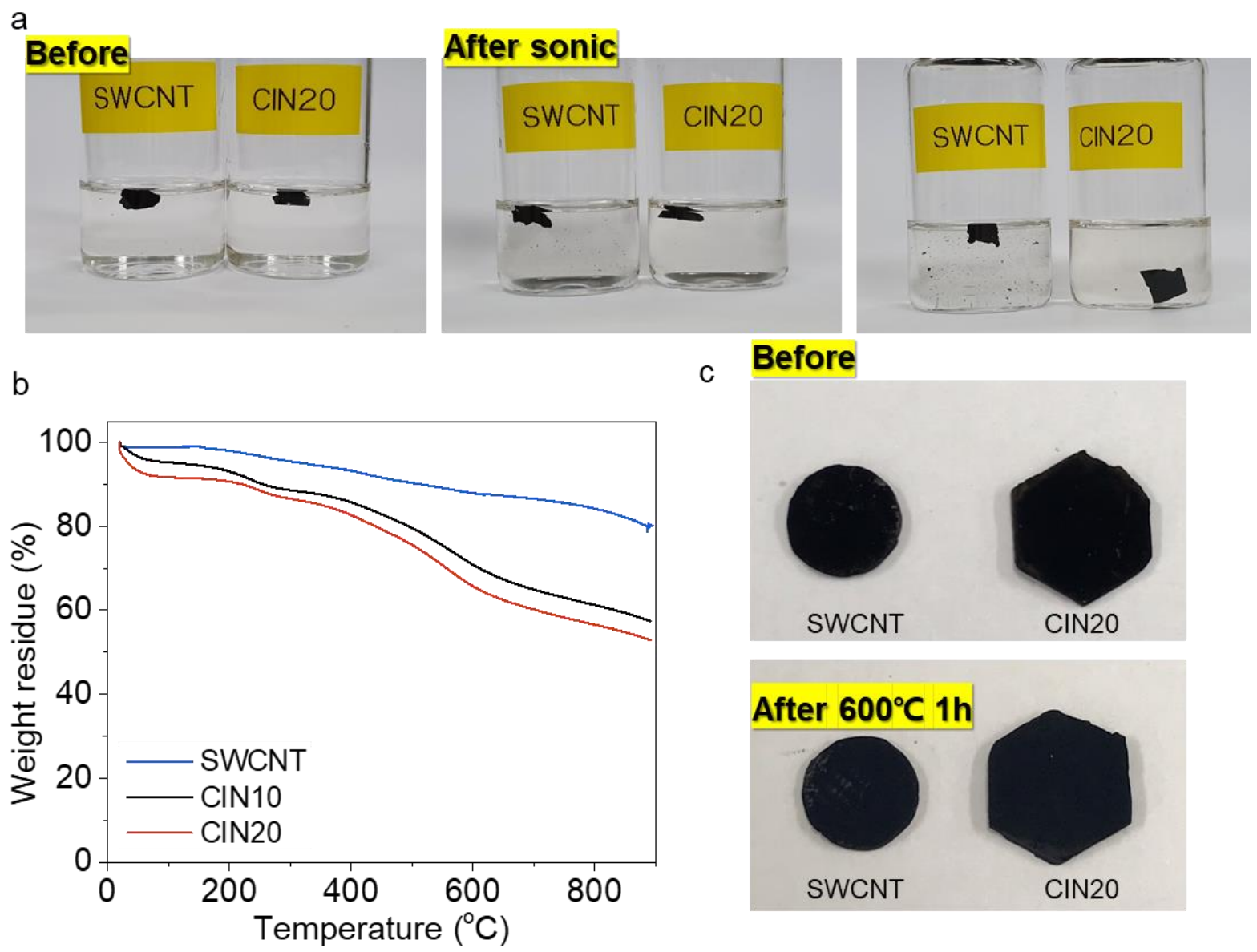

Figure S7. Chemical and thermal stability of SWCNT and CIN electrodes. (a) Photographs of SWCNT and CIN20 electrodes before and after sonication in the electrolyte. (b) TGA under Ar atmosphere results of SWCNT, CIN10, and CIN20 electrodes. (c) Optical images of SWCNT and CIN20 electrode after thermal annealing at $600^{\circ} \mathrm{C}$ for $1 \mathrm{~h}$. 

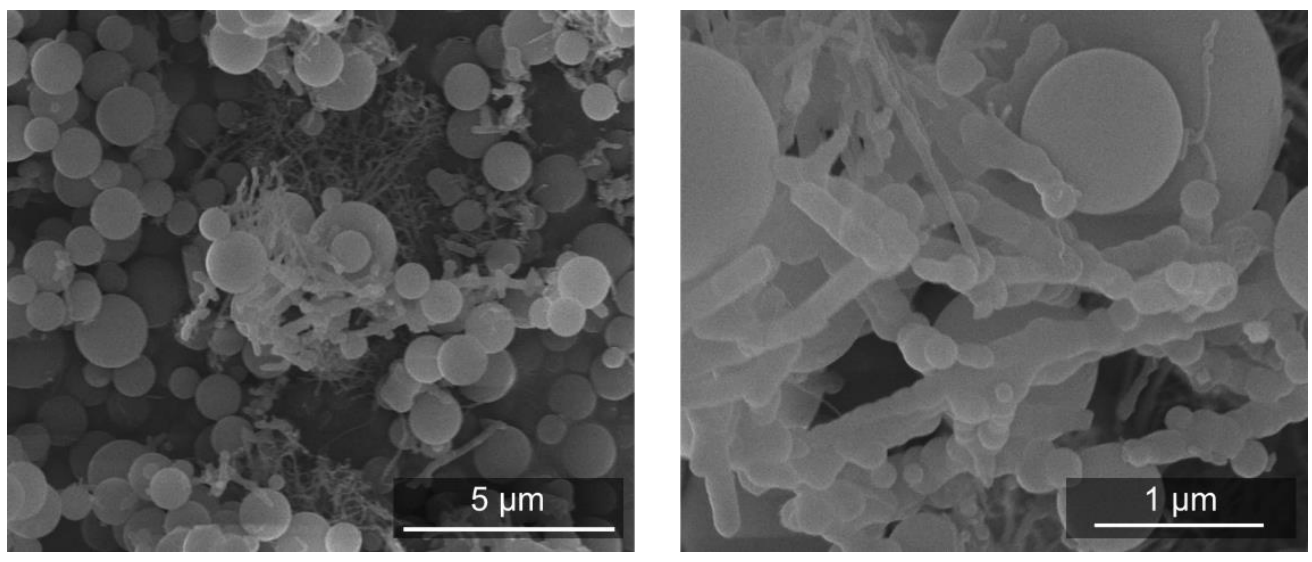

Figure S8. SEM images of the IBN coating process with a higher concentration of $30 \mathrm{mg} / \mathrm{ml}$ on the compressed SWCNT showing irregularly coated SWCNT films along with large amounts of isolated IBN microparticles. 

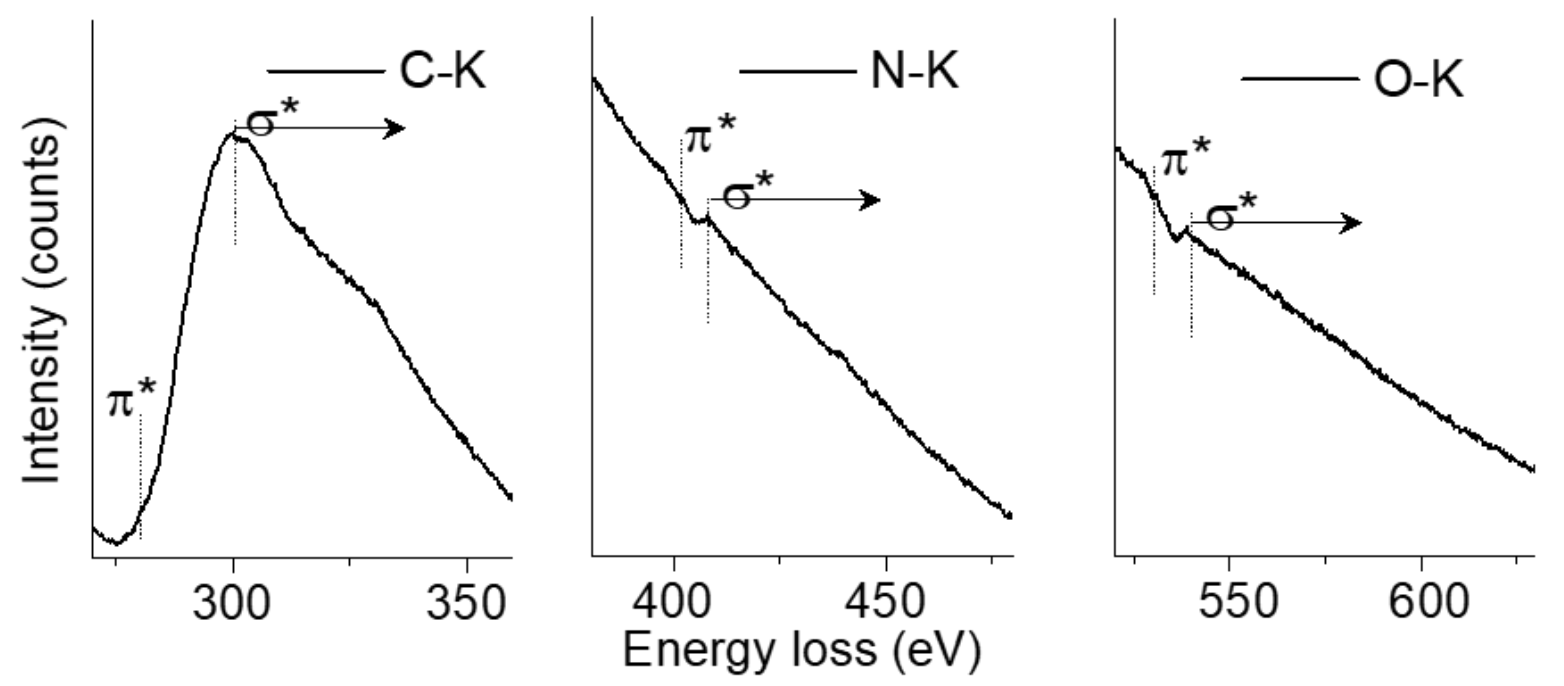

Figure S9. Electron energy loss spectroscopy (EELS) spectra of the core loss region of carbon, nitrogen, and oxygen K-edges. 

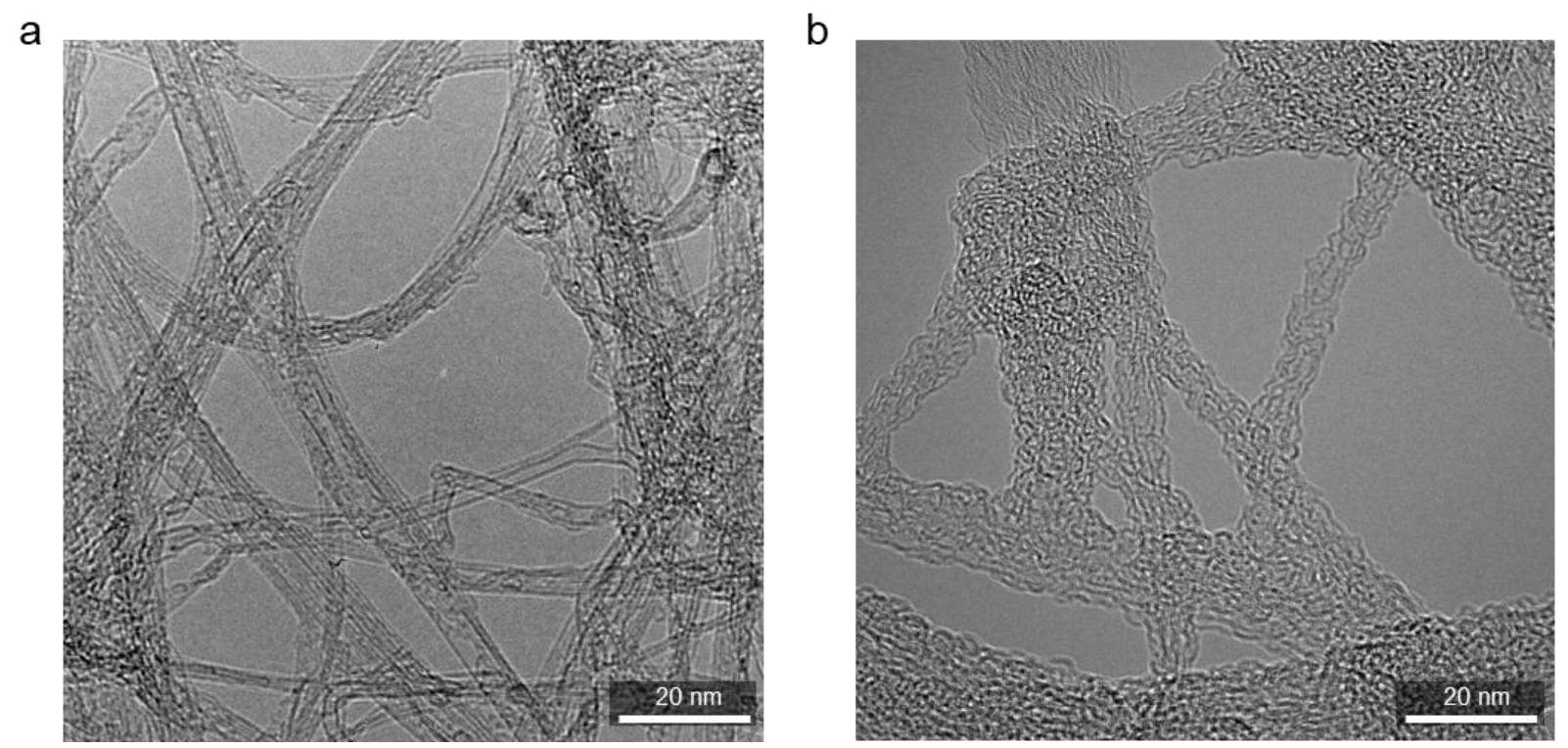

Figure S10. High magnification TEM images of bare SWCNT and CIN10, showing approximately 1.2-1.5 $\mathrm{nm}$ and $5.0 \mathrm{~nm}$ of diameters, respectively. 

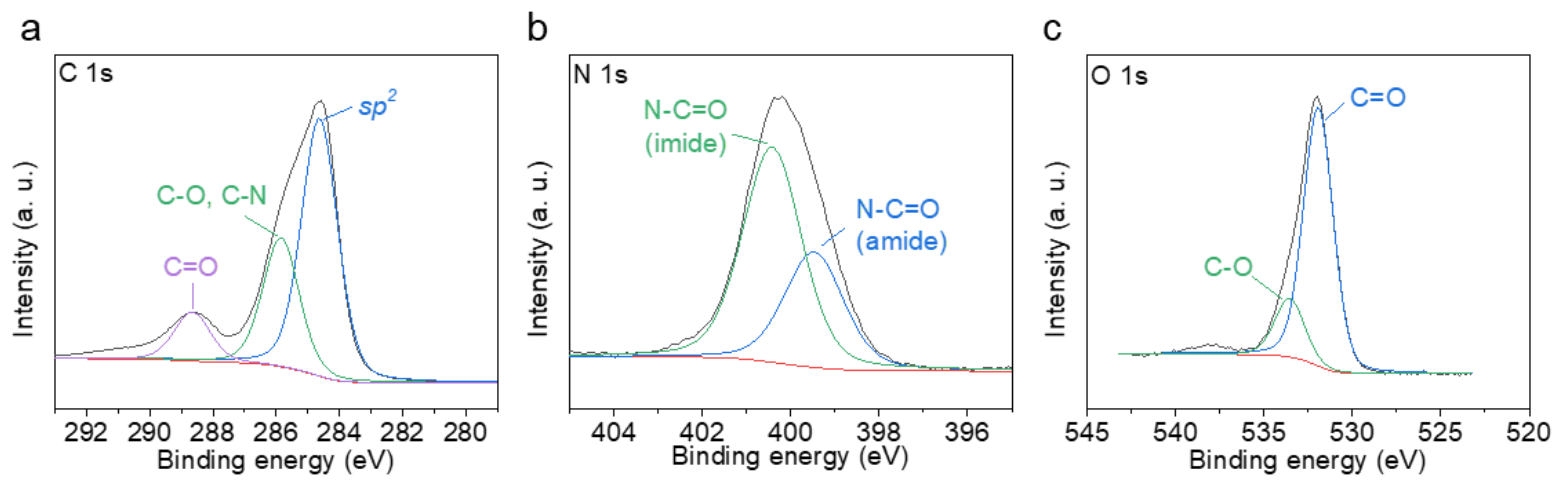

Figure S11. XPS spectra of (a) C 1s, (b) N 1s, and (c) O 1s of the CIN20. The peaks in the deconvolution of the $\mathrm{C}$ 1s spectrum of CIN20 at $284.6 \mathrm{eV}, 285.9 \mathrm{eV}$, and 288.7 are attributed to the $\mathrm{C}-\mathrm{C}$ from the $\mathrm{sp}^{2}$ carbon, $\mathrm{C}-\mathrm{O} / \mathrm{C}-\mathrm{N}$, and $\mathrm{C}=\mathrm{O}$ bonds respectively. The peaks in $\mathrm{N} 1 \mathrm{~s}$ spectrum at $399.5 \mathrm{eV}$ and $400.5 \mathrm{eV}$ are attributed to nitrogens at amide and imide bonds, respectively. The deconvoluted peaks in $\mathrm{O} 1 \mathrm{~s}$ at $532.0 \mathrm{eV}$ and $533.6 \mathrm{eV}$ are assigned to $\mathrm{C}=\mathrm{O}$ and $\mathrm{C}-\mathrm{O}$, respectively. 
a

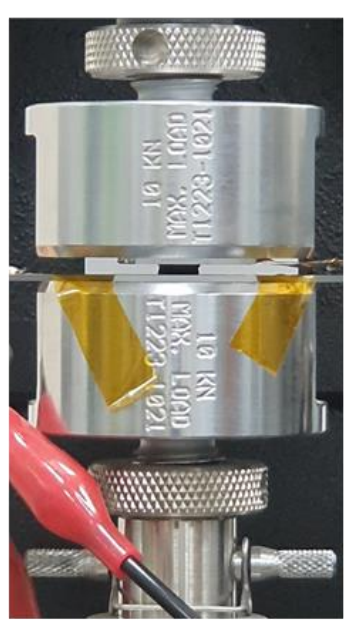

b

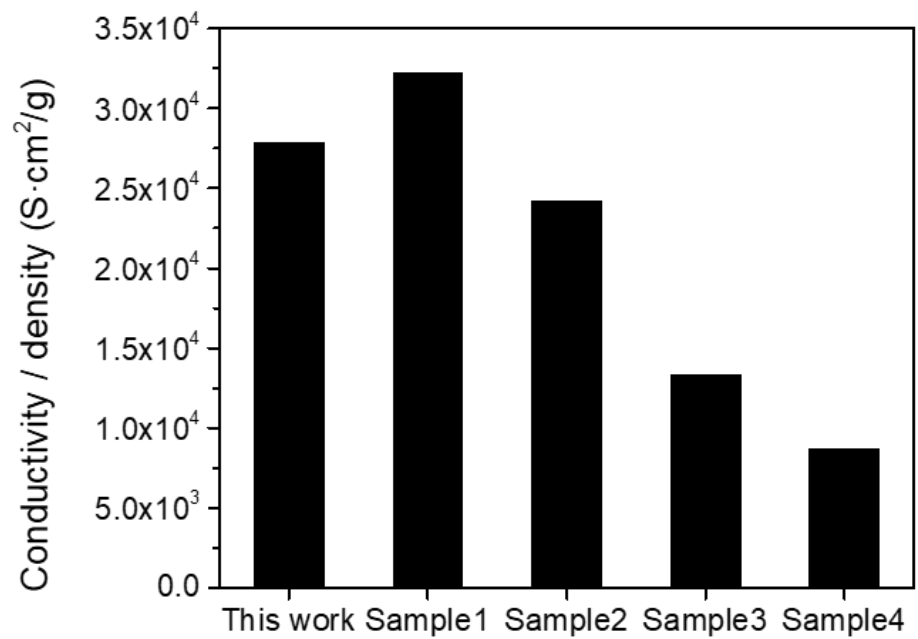

Figure S12. (a) Photograph of set-up for compressive stress-strain and electrical conductance measurements. (b) Conductivity comparison of different carbon scaffold normalized by their density (Sample1: CNT buckypaper, ${ }^{1}$ Sample2: Graphene foam, ${ }^{2}$ Sample3: CNT aerogel, ${ }^{3}$ and Sample4: Graphene aerogel $\left.{ }^{4}\right)$. 
a

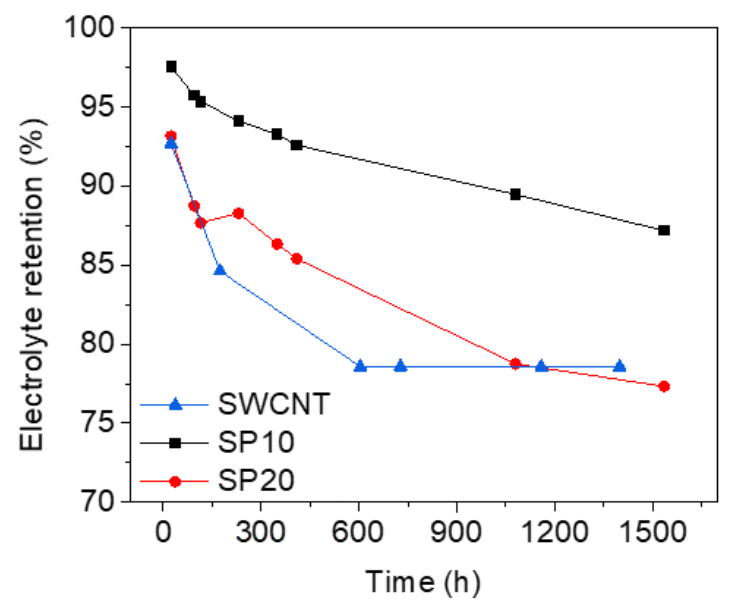

b

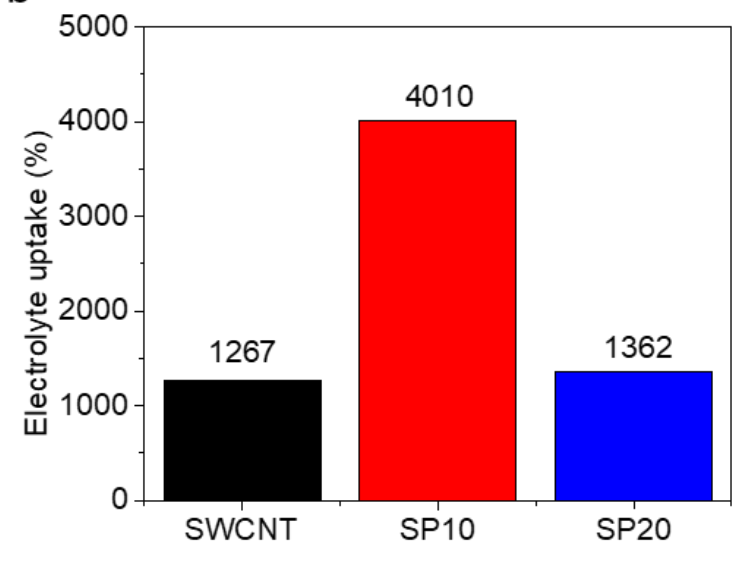

Figure S13. (a) Electrolyte retentions and (b) electrolyte uptake of three different electrodes. The electrolyte used here is $1.0 \mathrm{M}$ lithium hexafluorophosphate $\left(\mathrm{LiPF}_{6}\right)$ in ethylene carbonate $(\mathrm{EC}) /$ diethylene carbonate $(\mathrm{DEC})(1: 1, \mathrm{v} / \mathrm{v})$. 

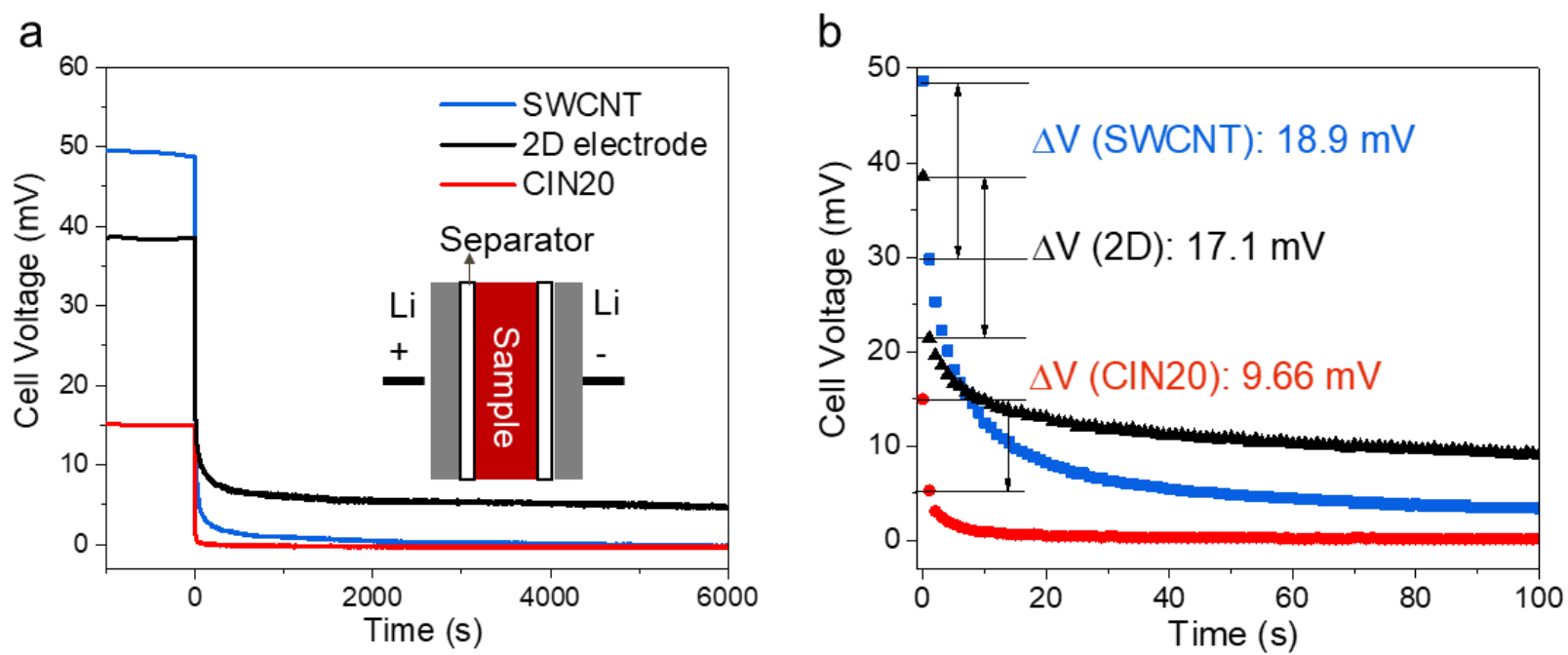

Figure S14. Tortuosity measurement. (a) Polarization-depolarization of symmetric cells (inset is a schematic illustration of the symmetric cell configuration for measurement of Li-ion diffusivity).

(b) Enlarged voltage profiles of (a) showing different ohmic resistances. 

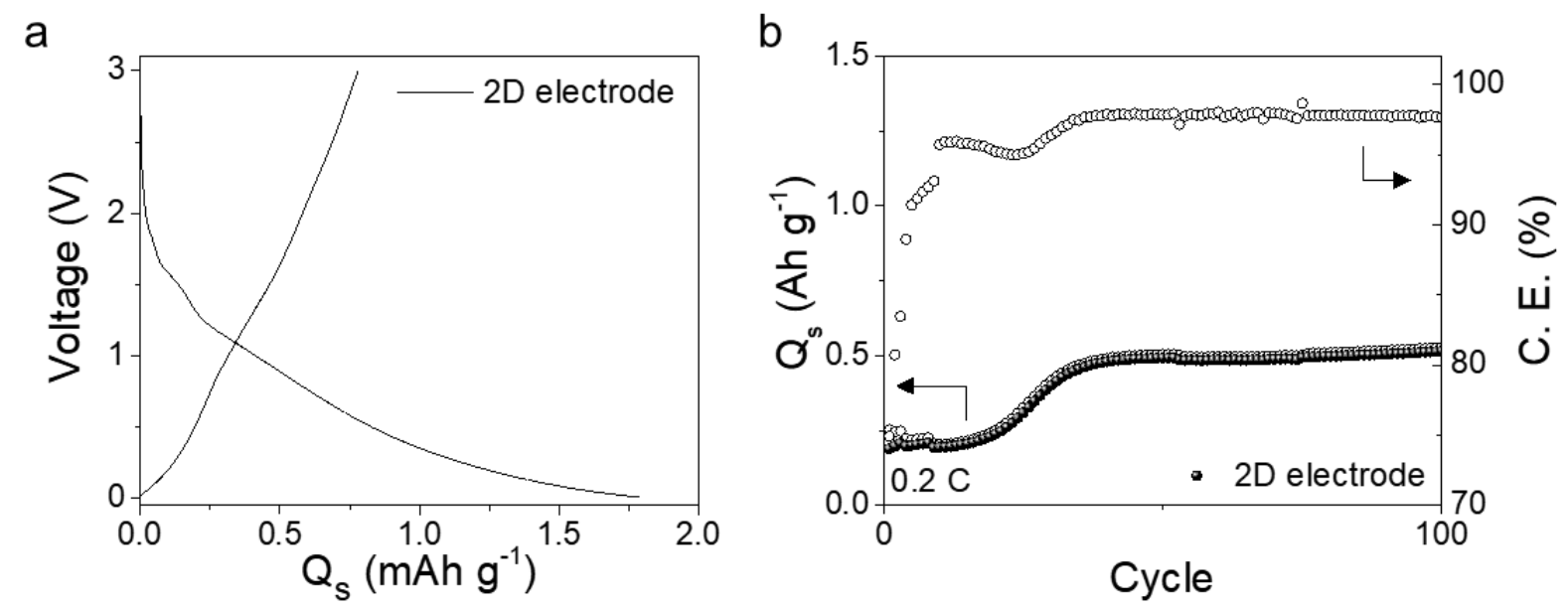

Figure S15. Electrochemical properties of 2D IBN electrode. (a) Voltage profile at the first cycle $0.05 \mathrm{C}$ and (b) cycle retention of the 2D IBN electrode at $0.2 \mathrm{C}$. 


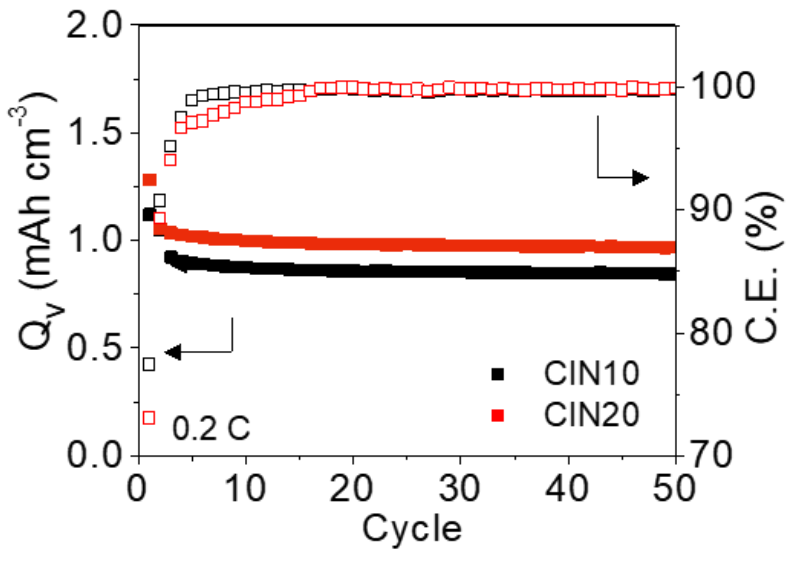

Figure S16. Coulombic efficiency and volumetric capacity plots of CIN10 and CIN20 electrodes. 

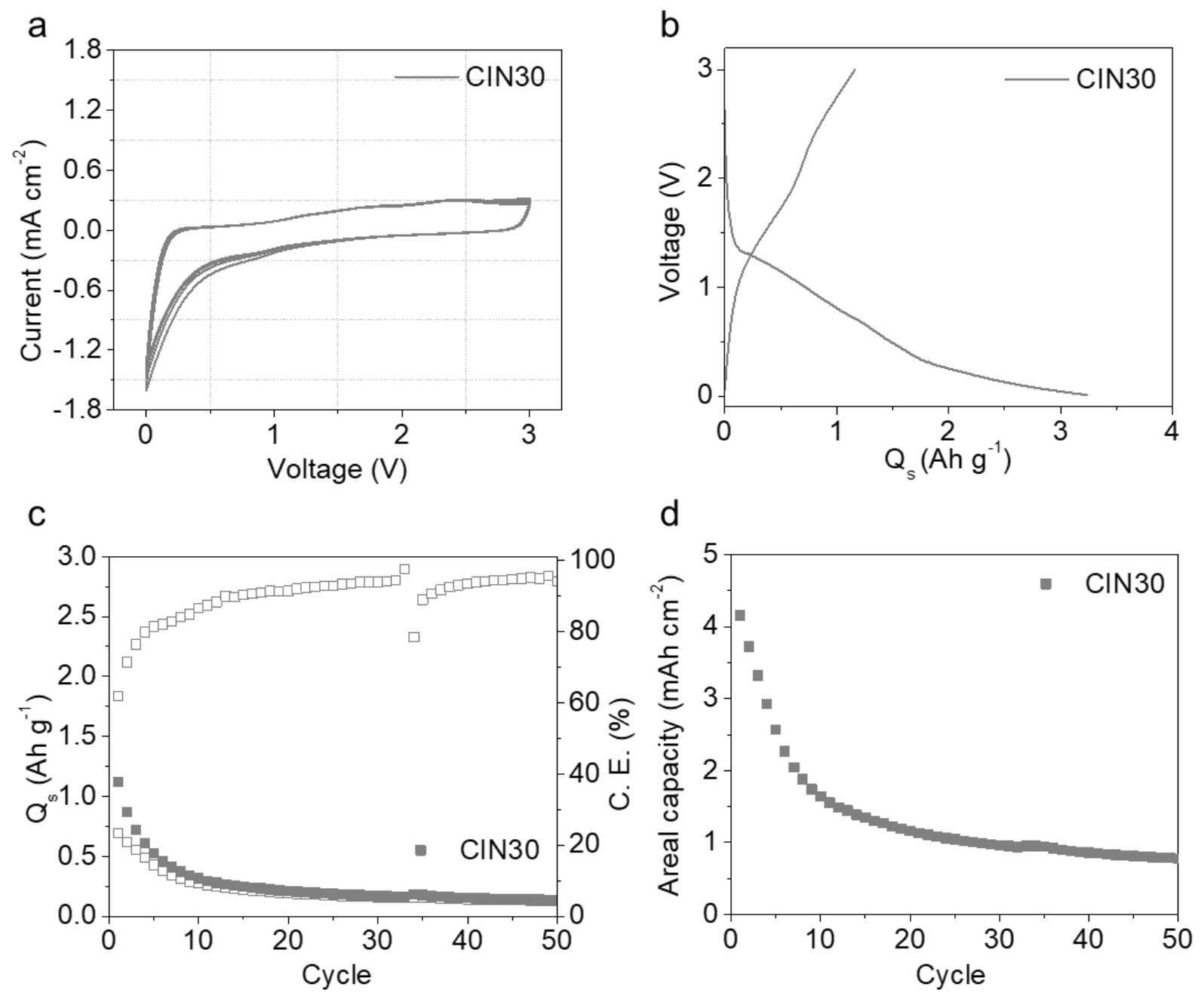

Figure S17. Electrochemical performances of CIN30 electrodes. (a) CV curves at $0.1 \mathrm{mV} \mathrm{s}^{-1}$, (b) galvanostatic voltage profile, (c) cycle retention at $0.2 \mathrm{C}$, and (d) areal capacity retention of CIN30 electrode. 
a

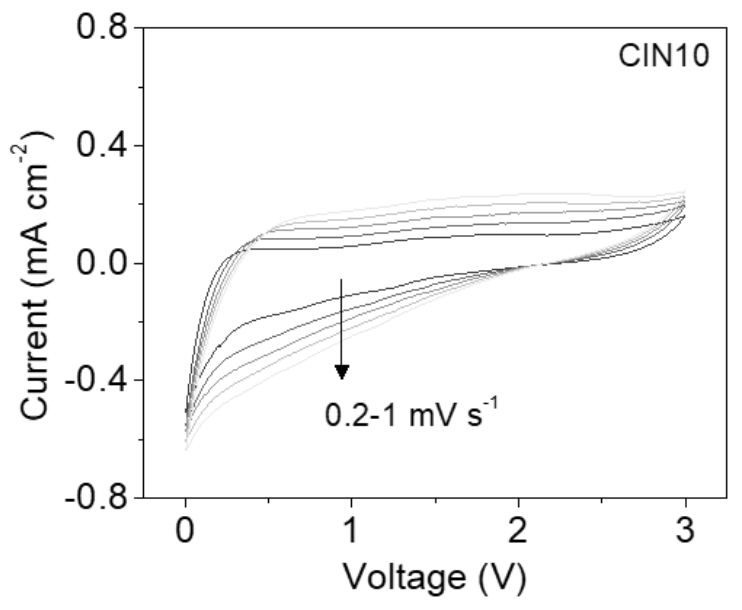

b

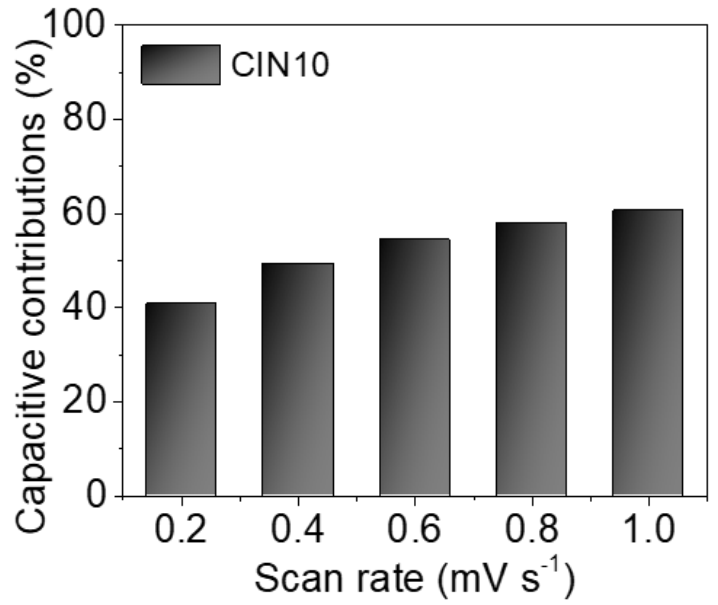

Figure S18. Kinetic analysis of CIN10 electrode. (a) CV curves at various scan rates and (b) capacitive contribution of CIN10 electrode. 

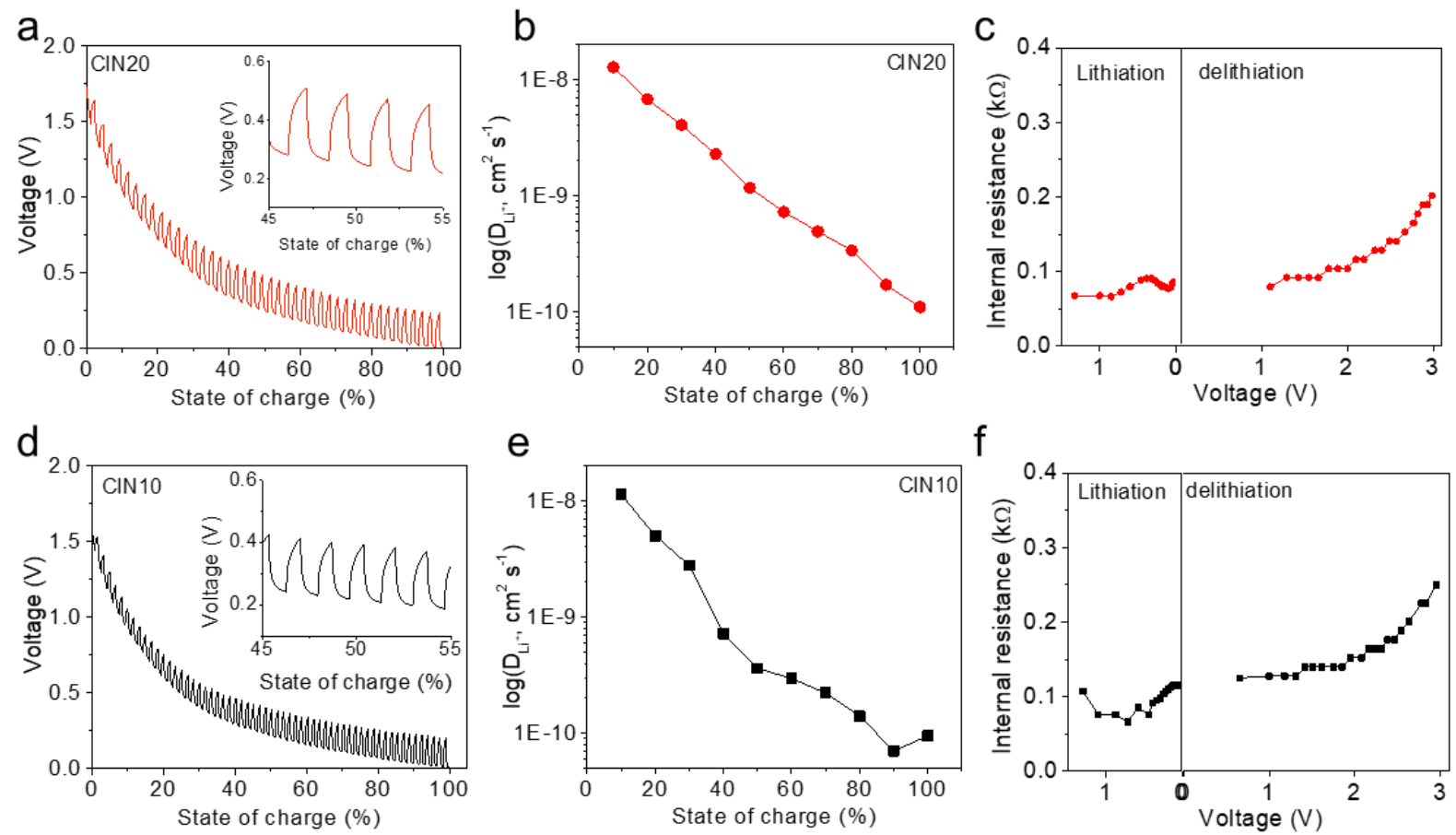

Figure S19. GITT analysis of CIN10 and CIN20 electrodes. Voltage profiles in GITT measurement, calculated diffusion coefficient according to the state of charge, and the internal resistance of CIN20 (a-c) and CIN10 (d-f) electrodes. 

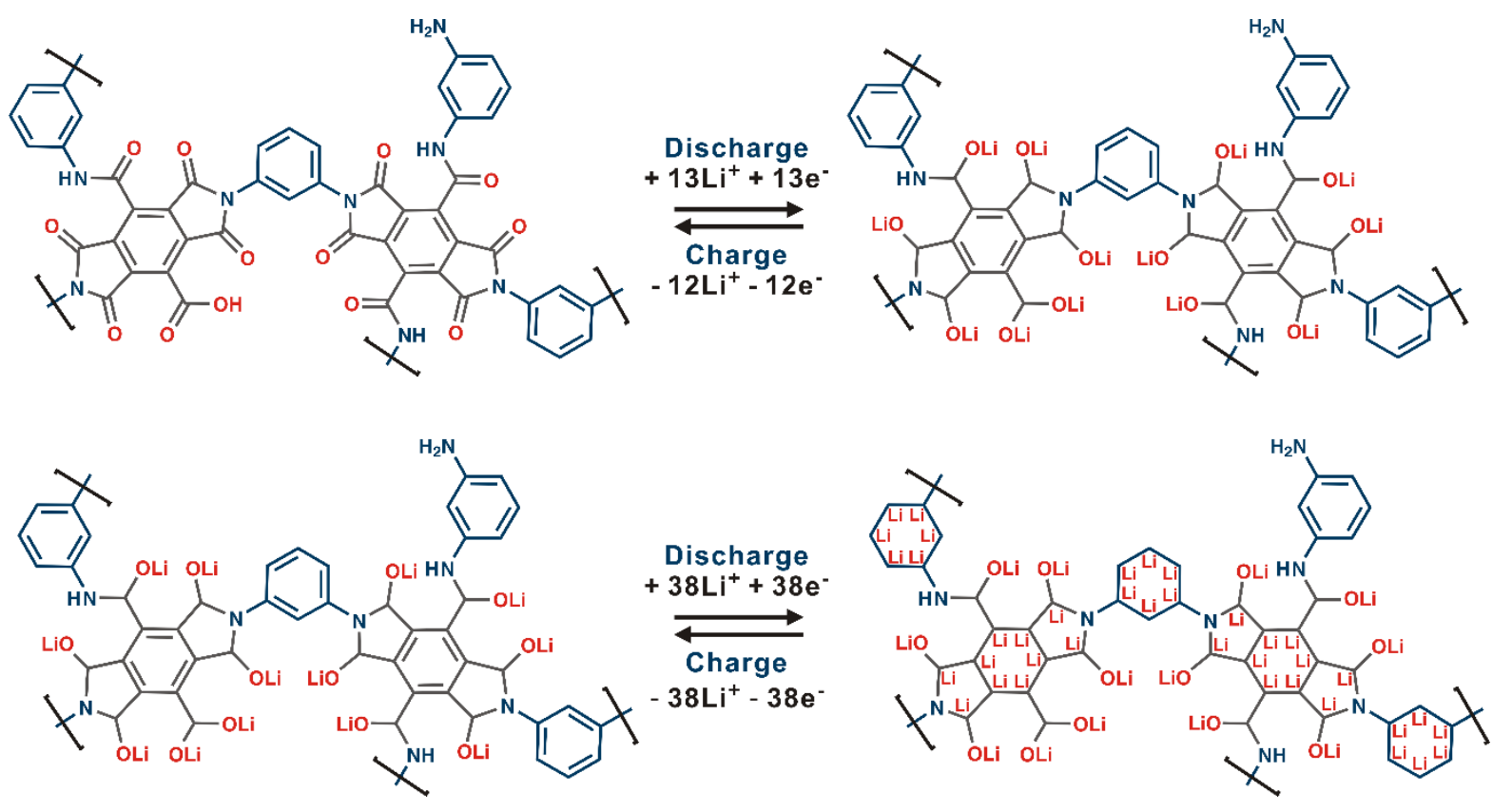

Figure S20. The proposed lithium storage mechanism of IBN layer. The irreversible reaction of Li with carboxylic acid group contributes to the different number of $\mathrm{Li}$ at the first stage of lithiation. 

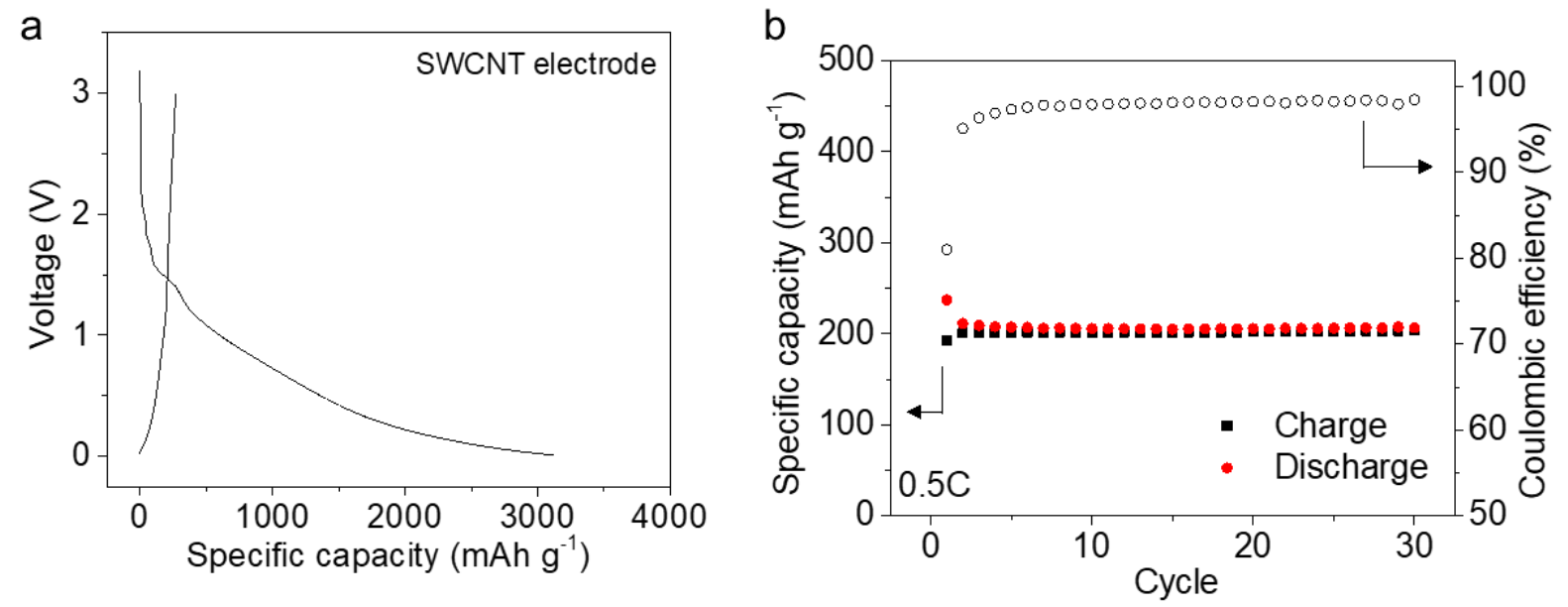

Figure S21. Electrochemical properties of SWCNT electrode. a) Voltage profile at the first cycle at $0.05 \mathrm{C}$ and b) Capacity retention at $0.5 \mathrm{C}$ of SWCNT electrode. 
a

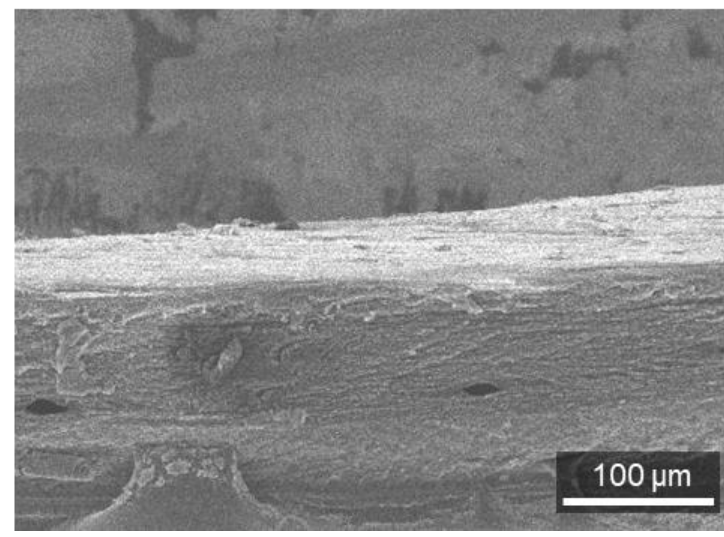

b

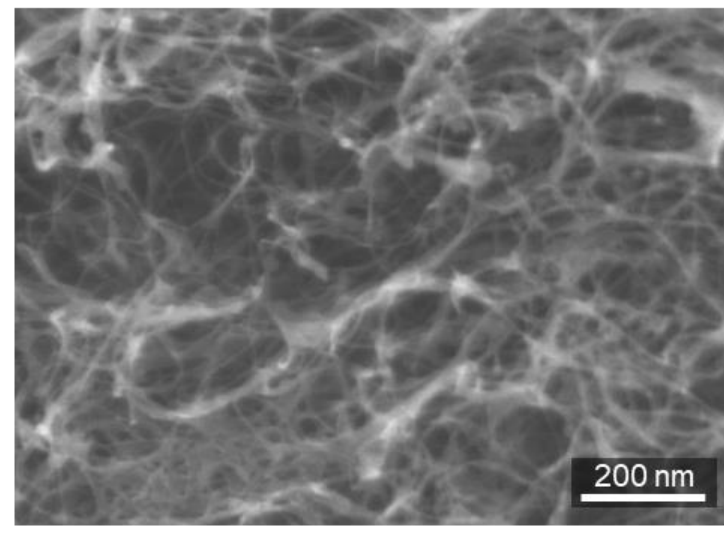

Figure S22. SEM images of CIN20 electrode after 100 cycles. 
a

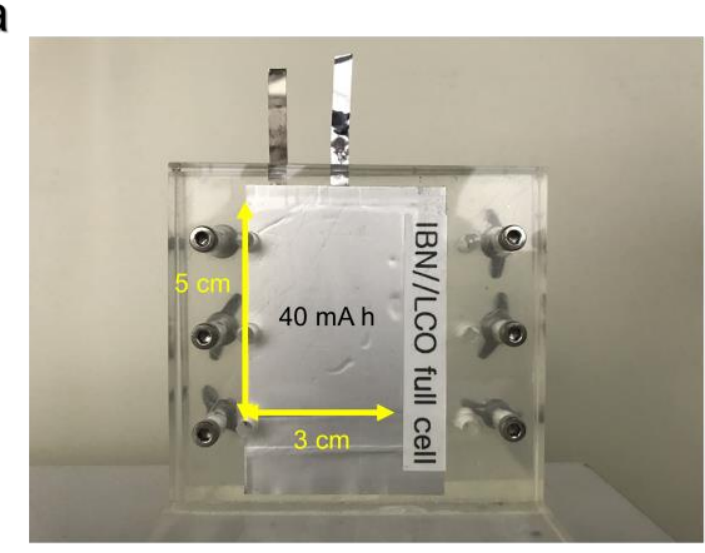

b
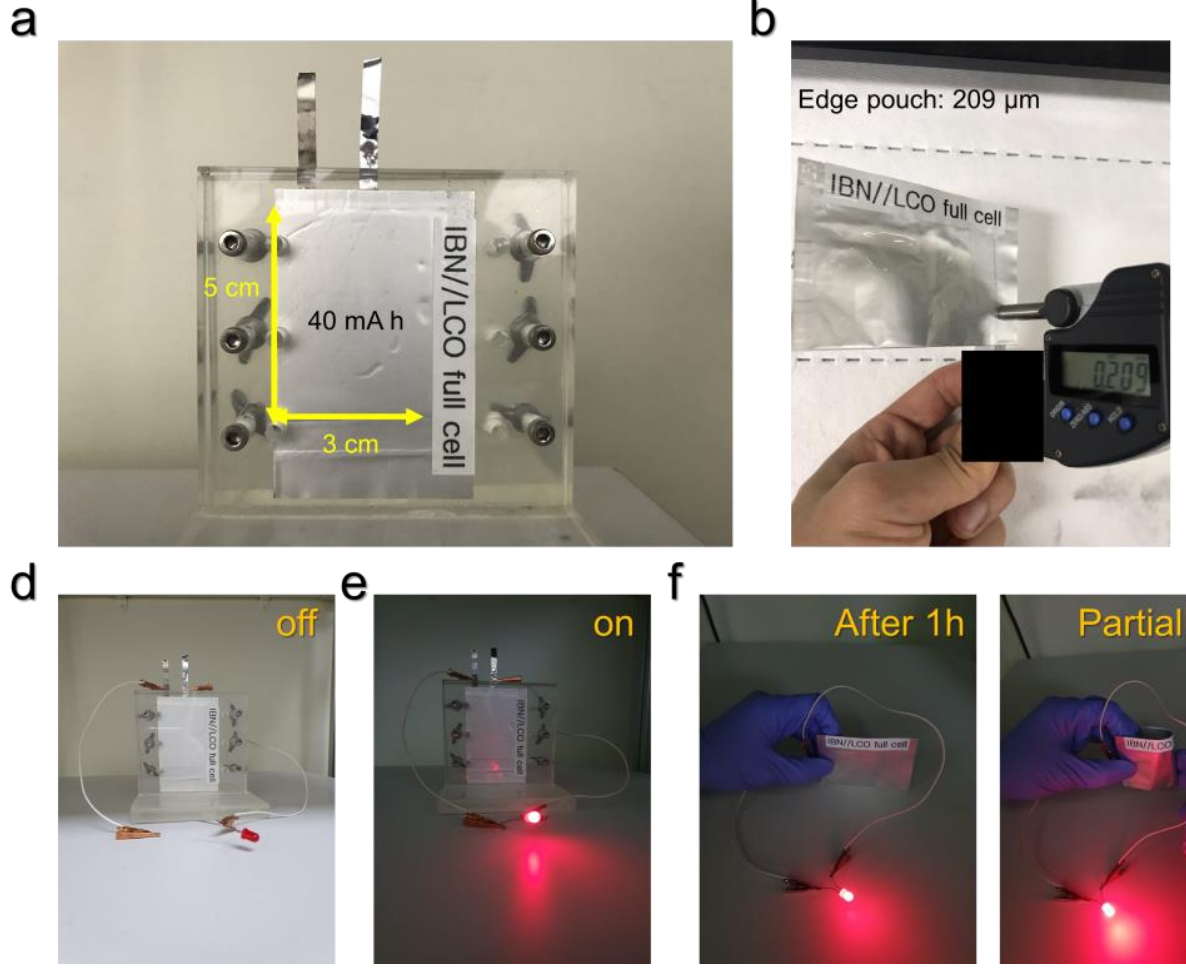

$f$

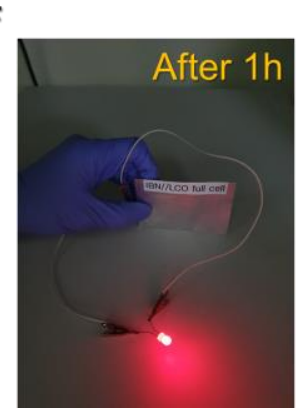

C

Center: $426 \mu \mathrm{m}$ (Net thickness:217 $\mu \mathrm{m}$ )
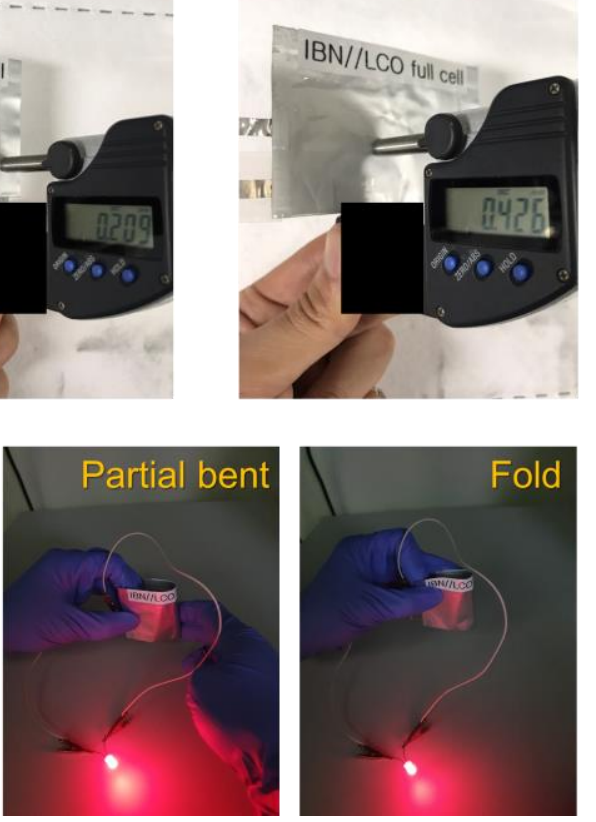

Figure S23. Demonstration of the pouch-type CIN-based full cell (labelled as IBN//LCO full cell).

(a) As-prepared pouch-type full cell $(40 \mathrm{~mA} \mathrm{~h})$, (b) Thickness of pouch $(209 \mu \mathrm{m})$, and (c) Thickness of full cell $(217 \mu \mathrm{m})$ consisting of $60 \mu \mathrm{m}$ of cathode, 5 layers of separator coiled over the cathode and anode to hold the structure $(115 \mu \mathrm{m}), \mathrm{Al}$ current collector for cathode $(20 \mu \mathrm{m})$, and $\sim 22 \mu \mathrm{m}$ of anode. 


\section{References}

(1) Wang, D.; Song, P.; Liu, C.; Wu, W.; Fan, S. Highly Oriented Carbon Nanotube Papers Made of Aligned Carbon Nanotubes. Nanotechnology 2008, 19, 075609

(2) Hu, G.; Xu, C.; Sun, Z.; Wang, S.; Cheng, H.-M.; Li, F.; Ren, W. 3D Graphene-FoamReduced-Graphene-Oxide Hybride Nested Hierarchical Networks for High-Performance Li-S Batteries. Adv. Mater. 2016, 28, 1603-1609.

(3) Bryning, M. B.; Milkie, D. E.; Islam, M. F.; Hough, L. A.; Kikkawa, J. M.; Yodh, A. G. Carbon Nanotube Aerogels. Adv. Mater. 2007, 19, 661-664.

(4) Worsley, M. S.; Pauzauskie, P. J.; Olson, T. Y.; Biener, J.; Satcher, J. H. Jr.; Baumann, T. F. Synthesis of Graphene Aerogel with High Electrical Conductivity. J. Am. Chem. Soc. 2010, 132, 14067-14069. 